\title{
Biossegurança e a enfermagem nos cuidados clínicos: contribuições para a saúde do trabalhador*
}

\author{
Biosecurity and clinical care nursing: contributions for the promotion of worker's health \\ Biosecuridad y la enfermería en la atención clínica: contribuciones para promoción de la salud del trabajador
}

\section{Samanta Rauber Gallas', Rosane Teresinha Fontana'}

'Universidade Regional Integrada do Alto do Uruguai e das Missóes. Curso de Enfermagem. Grupo de Estudos e Pesquisas em Enfermagem, Educação e Saúde. Santo Ângelo, RS

Submissão: 3 1/07/2009

Aprovação: 10/07/2010

\section{RESUMO}

Estudo Qualitativo Que teve como objetivo investigar concepções e práticas de técnicos em enfermagem acerca da biossegurança e sua interface com os riscos biológicos, desenvolvido com vinte trabalhadores de uma unidade de cuidado clínico, de um hospital do interior do Rio Grande do Sul. Os dados foram coletados mediante entrevistas e observação sistemática. A análise temática foi a metodologia usada para o tratamento dos dados. A negligência dos trabalhadores Quanto ao uso de Equipamentos de Proteção individual e a sobrecarga de trabalho são fatores de risco para os acidentes com material biológico. Sugerem-se parcerias entre os atores envolvidos no cuidado para a construção de ambientes saudáveis e responsabilização por negligências à biossegurança.

Descritores: Exposição a agentes biológicos; Saúde do trabalhador; Equipe de enfermagem

\section{ABSTRACT}

Qualitative study that aimed at investigating concepts and practices of nursing technicians on biosecurity and its interface with biological hazards, with 20 workers developed a clinical care unit of a hospital in the interior of Rio Grande do Sul. Data were collected through interviews and systematic observation. Thematic analysis was the methodology used for data processing. The negligence of its employees on the use of individual protection equipment and work overload are risk factors for accidents with biological material. Suggested that partnerships between the actors involved in caring for the construction of healthy environments and accountability for negligence on biosecurity.

Descriptors: Exposure to biological agents; Occupational health; Nursing, team.

\section{RESUMEN}

Estudio cualitativo Que tuvo como objetivo estudiar los conceptos y prácticas de los técnicos de enfermería sobre seguridad de la biotecnología y su interrelación con los factores biológicos, con veinte trabajadores desarrollado una unidad clínica de un hospital en el interior de Rio Grande do Sul Los datos fueron recolectados a través de entrevistas y observación sistemática. El análisis temático fue la metodología utilizada para el procesamiento de datos. La negligencia de sus empleados sobre el uso de equipos de protección individual y la sobrecarga de trabajo son factores de riesgo de accidentes con material biológico. Sugirió Que las asociaciones entre los actores involucrados en el cuidado de la construcción de ambientes saludables y la responsabilidad por negligencia en materia de bioseguridad.

Descriptores: Exposición a agentes biológicos; Salud laboral; Grupo de enfermería

* Artigo original apoiado pelo GEPESE (Grupo de Estudos e Pesquisas em Enfermagem, Educação e Saúde) da Universidade Regional Integrada do Alto do Uruguai e das Missões, campus Santo Ângelo, RS.

\section{AUTOR CORRESPONDENTE Rosane Teresinha Fontana. Rua Sete de Setembro, I I26/401. CEP 98800-000. Santo Ângelo, RS. \\ E-mail: rfontana@urisan.tche.br}




\section{INTRODUÇÃO}

Por volta dos anos 1970, iniciaram-se as discussões envolvendo a proteção e segurança dos trabalhadores, principalmente aQueles envolvidos com pesquisa em organismos geneticamente modificados. A partir daí, a Questão da exposição ocupacional e o conceito de biossegurança foram sendo desenvolvidos e introduzidos pela comunidade científica, com foco, inicialmente, nos trabalhadores dos laboratórios de análise de material biológico, considerando-se a incidência, nestes profissionais, de doenças como a tuberculose e hepatite $\mathrm{B}^{(1-2)}$.

Sabe-se Que, em grande parte dos cenários de prestação de cuidados de enfermagem, negligenciam-se normas de biossegurança; os equipamentos de proteção individual (EPI) são mais utilizados na assistência ao paciente cujo diagnóstico é conhecido, subestimando-se a vulnerabilidade do organismo humano a infecções ${ }^{(3)}$. O recomendável é Que o trabalhador proteja-se sempre Que tiver contato com material biológico e, também, durante a assistência cotidiana aos pacientes, independente de conhecer o diagnóstico ou não, utilizando-se, portanto, das precauções universais padrão(4). Estudos demonstram Que as maiores causas de acidentes punctórios, entre os trabalhadores da enfermagem, estão nas práticas de risco como o reencape de agulhas, o descarte inadequado de objetos perfurocortantes e a falta de adesão aos $\mathrm{EPI}^{(5-6)}$.

Além disso, em grande parte dos casos de exposição a material biológico, o status do paciente fonte não é conhecido, o Que potencializa o risco de adeuirir doenças como o HIV, hepatite B e hepatite C. A exposição ocupacional é uma importante fonte de infecção por esses vírus. Um estudo demonstrou que a cobertura vacinal contra hepatite $B$ dos trabalhadores da saúde envolvidos com os acidentes estava em torno de aproximadamente 73\%, evidenciando o risco de infecção pelo HBV em aproximadamente $27 \%$ dos trabalhadores Que não haviam completado o esQuema vacinal $^{(7)}$.

Como se pode perceber, algumas evidências científicas demonstram que o risco para acidentes com material biológico é uma realidade configurada em muitos cenários. Considerando-se essas informações e o fato de Que os trabalhadores da área da saúde encontram-se em permanente contato com agentes biológicos (vírus, bactérias, parasitas, geralmente associados ao trabalho em hospitais e laboratórios e, até mesmo na agricultura e pecuária) ${ }^{(8)}$, é fundamental, portanto, a observância dos princípios de biossegurança na assistência aos pacientes e no tratamento de seus fluidos, bem como no manuseio de materiais e objetos contaminados em todas as situações de cuidado e não apenas Quando o pacientefonte é sabidamente portador de alguma doença transmissível.

É válido salientar Que em muitos locais de atuação da enfermagem, são insatisfatórias as condições de trabalho, evidenciadas por problemas de organização, deficiência de recursos humanos e materiais e área física inadequada do ponto de vista ergonômico. Acredita-se Que esta conformação é fator preditivo para a exposição a riscos ocupacionais.

Neste panorama, é instituída a Norma Regulamentadora número 32 (NR 32) ${ }^{(9)}$, do Ministério do Trabalho e Emprego(BR) Que trata da Segurança e Saúde no Trabalho em Serviços de Saúde, com o objetivo de agrupar o Que já existe no país em termos de legislação e favorecer os trabalhadores da saúde em geral, estabelecendo diretrizes para implementação de medidas de proteção à saúde e segurança dos mesmos. Esta norma trata dos riscos biológicos; dos riscos Químicos; das radiações ionizantes; dos resíduos; das condições de conforto por ocasião das refeições; das lavanderias; da limpeza e conservação; e da manutenção de máQuinas e equipamentos em serviços Que prestam assistência à saúde.

Sendo os acidentes ocupacionais com perfuro cortantes ou por contato de secreções com mucosas muito comuns entre os trabalhadores da enfermagem ${ }^{(10-1)}$, optou-se por pautar neste estudo a biossegurança contra riscos biológicos, de modo a propor reflexões acerca destas exposições. Sendo assim, este estudo justifica-se na medida em Que oferece um espaço para Que o profissional da enfermagem reflita sobre a biossegurança individual, bem como para levantar crenças e saberes dos trabalhadores sobre o tema, para Que se possam propor medidas Que diminuam os indicadores de adoecimento decorrentes de agravos relacionados.

O objetivo geral dessa pesQuisa foi investigar concepções e práticas dos técnicos em enfermagem acerca da biossegurança e sua interface com os riscos biológicos.

\section{MÉTODOS}

Tratou-se de uma pesquisa Qualitativa, pois foram explorados conhecimentos sobre a realidade, Que só podem ser obtidos pela descrição da experiência dos próprios atores Que a vivenciam, com a finalidade de explorar e explicitar o fenômeno, além de proporcionar ao pesquisador maior familiaridade com o mesmo ${ }^{(12)}$.

Foram critérios para seleção dos sujeitos: ser técnico em enfermagem da unidade em estudo e aceitar participar. Fizeram parte do estudo vinte técnicos em enfermagem. Optou-se por estudar a exposição entre técnicos em enfermagem considerando Que, pela natureza de sua ocupação, são trabalhadores Que estão, mais frequentemente, em contato com fluidos e sangue, e, também, por tratar-se de um cenário onde o técnico trabalha sob riscos em virtude da grande demanda e, conseeüente superlotação da unidade.

O local escolhido, intencionalmente, para o estudo foi a unidade de cuidado clínico adulto, de um hospital de médio porte, localizado na região noroeste do estado do Rio Grande do Sul, tendo em vista Que esta unidade funciona, cotidianamente, com grande rotatividade e demanda de entradas e saídas de pacientes, caracterizando-se como uma unidade 'agitada'.

A unidade de internação em cuidado clínico do referido hospital atende pacientes conveniados pelo Sistema Único de Saúde (SUS), sendo que a média mensal é de, aproximadamente, 250 internações. Para atendê-las, conta com 41 leitos, sendo dois de isolamento e 12 psiquiátricos; e 20 técnicos em enfermagem, dois enfermeiros, contando, também, com dois bolsistas de enfermagem.

A coleta dos dados foi feita mediante entrevistas com os sujeitos. Para tanto, foi utilizado um instrumento com perguntas não estruturadas. A fim de complementar os dados obtidos pela entrevista, realizou-se uma observação sistemática para a verificação da adesão do hospital à NR $32^{(9)}$, a Qual normaliza ações para a segurança e saúde do trabalhador em serviços da área. Para tanto, foi utilizado um roteiro estruturado, construído e adaptado pelos pesQuisadores, em conformidade com a referida NR e pautado nas ações de prevenção aos riscos biológicos. 
A categorização temática ${ }^{(14)}$ foi o referencial para a análise dos dados. A transcrição e organização dos relatos obtidos pela entrevista e pelo registro da observação constituíram a ordenação dos dados e a classificação deu-se a partir da leitura exaustiva destes materiais identificando-se estruturas de relevância, de onde emergiram cinco categorias: Os riscos do trabalho sob a ótica dos técnicos em enfermagem; A punção venosa como atividade de risco; A negligência do trabalhador: o não uso dos EPI; Contribuições da equipe de enfermagem e dos gestores para a prevenção dos acidentes de trabalho por material biológico; A gestão de enfermagem contribuindo para a prevenção de acidentes com material biológico. A partir destas etapas, estabeleceram-se articulações entre a teoria e a prática.

Foram respeitados os preceitos éticos para pesquisas com seres humanos estabelecidos na resolução 196/96 do Conselho Nacional de Saúde ${ }^{(13)}$ sendo Que o desenvolvimento do projeto só foi iniciado após a emissão do parecer favorável docomitês de ética em pesQuisa da Universidade Regional Integrada do Alto Uruguai e das Missões - campus de Santo Ângelo - protocolado sob n 098-04/PPH/08 e da autorização da instituição em estudo. Os sujeitos Que aceitaram participar do estudo assinaram um Termo de Consentimento Livre e Esclarecido.

\section{RESULTADOS E DISCUSSÃO}

Os riscos do trabalho sob a ótica dos técnicos em enfermagem

Ao investigar-se a concepção dos indivíduos acerca de sua exposição a riscos no ambiente de trabalho, percebe-se que os mesmos têm consciência dos perigos aos Quais estão submetidos por conseQüência de suas atividades laborais. Entre os pesquisados emerge uma grande preocupação com a exposição aos riscos biológicos no ambiente de trabalho, conforme evidenciado nas falas:

Ipreocupa] Contaminação com materiais perfuro cortantes [me preocupa]; acidentes com materiais perfuro cortantes; os pacientes acamados Que tem secreção contaminada, úlcera de pressão, ou paciente que faz uso de sonda, Que tem presença de secreção. (E I0)

Ipreocupal Material perfuro cortante Que a gente manipula, pacientes[...] com doença Que podem ser transmitidas. (EI3)

É importante observar Que os dispositivos de segurança ao descarte ainda não estão disponíveis para o uso, no cenário estudado, o que pode contribuir para o acidente. Conforme a NR 32, deve ser assegurado o uso de materiais perfuro cortantes com dispositivo de segurança e a responsabilidade do descarte é do trabalhador Que utilizar o objeto perfuro cortante $\mathrm{e}^{(9)}$.

Outra informação relevante Que parte da equipe é a relação existente entre o risco psicossocial e o risco biológico. Considerando-se Que a unidade interna pacientes em sofrimento psíquico e dependentes Químicos, a agitação e/ou agressão por parte dos pacientes psiquiátricos pode ser fator agravante para o acidente por material biológico, como demonstram as falas dos respondentes:

O risco de contaminação aumenta, [...] a gente corre o risco de se picar com algum paciente, risco de agressão de algum paciente, porque a gente aqui também trata com pacientes psiQuiátricos , muitos dependentes Químicos, então nós lidamos no meio de risco. (E I 4)

[...] tu se picar com uma agulha, por exemplo, ou de um paciente surtar, te atacar porQue tem a ala psiQuiátrica aQui, são inúmeros. (E19)

[...] pra mim é porque eu lido com paciente psiquiátrico, daí é mais arriscado porque perde acesso [...Jaí tu corre risco de ter contaminação através do sangue. (E I 8)

Os riscos de agressão e agitação dos pacientes também foram citados em outros estudos voltados para a saúde dos trabalhadores e, como determinantes de acidentes ${ }^{(10,15)}$. O cuidado ao paciente psiquiátrico ou agressivo pode, sim, ser fonte de risco, na medida em Que se agitando, o paciente favorece uma técnica incorreta, além de Que, um surto ou uma agressão pode gerar ansiedade no trabalhador, ocasionando dificuldades na execução da técnica, como a venóclise.

\section{A punção venosa como atividade de risco}

Quando indagados acerca da prática profissional Que mais os expõe ao risco de contaminação por materiais biológicos, a punção venosa surge como importante fator de risco ocupacional para a maioria dos sujeitos, Percebe-se, pelas falas, Que os profissionais não negligenciam outros fluidos responsáveis por doenças transmissíveis, porém o contato com o sangue aparece como a grande preocupação.

Olha, tem os pérfuros que a gente punciona que é, de alguma forma, um perigo, um risco Que a gente corre e também esses curativos com secreção Que sai, isso aí tudo é coisa contaminada Que facilita a gente pegar alguma doença. (E4)

A punção venosa, contato direto com paciente, ás vezes alguma secreção Que pode saltar no olho, tem um cortezinho na mão, então acho Que tudo é risco. (E5)

\section{[...JÉ na punção venosa Que corremos maior risco contaminação. E também os pacientes com tuberculose, hepatite, aids. (E9)}

Estudos demonstram Que o material perfuro cortante é o responsável pela maioria dos acidentes dos serviços de saúde, sendo as agulhas as maiores causadoras destes acidentes ${ }^{(10,16-19)}$, condizente com a preocupação dos trabalhadores.

Merecem destaQue as relevantes declarações dos entrevistados acerca dos acidentes sofridos durante a realização de um procedimento tido como simples pela maioria dos profissionais, o hemoglicoteste (HGT). Mesmo sem serem indagados a respeito das circunstâncias do acidente, a metade dos profissionais Que já esteve exposto a acidente com material biológico, destacou Que este aconteceu durante realização de HGT, através de picada com a agulha hipodérmica, como demonstrado na fala:

Eu acho que foi um descuido, e uma falta de atenção, porQue 
eu fiz um HGT num paciente e ao apertar o dedo do paciente não tinha largado a agulha, daí automaticamente eu piQuei meu dedo depois de já ter picado o paciente. (EI4)

Tal situação é preocupante considerando-se a baixa complexidade do procedimento em Questão. Um estudo epidemiológico Que analisou 616 acidentes de trabalho típicos aponta Que as agulhas hipodérmicas foram responsáveis pela maioria dos acidentes com perfuro cortantes ${ }^{(18)}$.

Da mesma forma Que em outros estudos ${ }^{(6,16,20)}$, as falas demonstram Que o reencape da agulha ainda é uma prática usada por alguns profissionais, embora amplamente discutida como uma prática insegura e vedada pela NR $32^{(9)}$.

Eu deveria estar usando luva, não estava usando luva e reencapei a agulha e o correto é não reencapar a agulha. Nem prestei atenção de usar luva. [...J Não estava usando completamente nada/ nenhum EPI]. (EIO)

Então as vez tu sai com uma bandeja superlotada[...] se tu não reencapar a agulha tu vai ficar com um número de agulhas soltas na tua bandeja bem grandes. Se tu não tivesse tanto acúmulo, ás vezes, se tu não corre, tu vai ficar com coisa pra trás e se tu correr, o risco aumenta. (E I6)

\section{A negligência do trabalhador: o não uso dos EPI}

Constatou-se Que, mesmo com os equipamentos de proteção individual à disposição dos funcionários para uso, um número significativo de pessoas admitiu não utilizá-los Quando necessário, conforme os depoimentos:

[...] eu não uso devido á pressa, ou como se diz, assim, os funcionários se acomodam e acham Que podem fazer sem proteção. Eu, por exemplo, uso luva sempre, mas óculos de proteção Quase nem coloco; por Que eu já uso óculos. (E2)

[a falta de uso]Eu acho que às vezes tem a pressa, o esquecimento, acaba Que as pessoas acham Que vão ir rápido, Que não vai acontecer nada, e acham Que não precisa usar. Acho Que isso é descuido também, por parte do funcionário. (E 5)

eu acho que isso vai do descuido de cada um, cada funcionário, ou na correria, tu sai correndo pra atender um paciente, pra ver alguma coisa, tu esquece de colocar uma máscara, esquece de colocar uma luva. (E I4)

De acordo com a maioria dos entrevistados, a autoconfiança, o descuido e a pressa são fatores Que contribuem para a omissão/ negligência da equipe no uso dos EPI. Muitos acreditam, ainda, Que alguns EPI atrapalham o desenvolvimento das técnicas. Ora, se os EPI são considerados desconfortáveis, a incorporação ao seu uso é dificultada. Trata-se, então, muito mais do Que incentivar o uso, oferecer EPI adequados ao tamanho e a estrutura anatômica de Quem usa.

Supõe-se que, pelo fato de considerar Que possui domínio da técnica, o trabalhador dispense os equipamentos de proteção, desconsiderando sua vulnerabilidade e expondo-se aos riscos ocupacionais. Resultados semelhantes foram encontrados em estudos relatando práticas da negligência ao uso de EPI, seja por omissão ou por uso incorreto ${ }^{(3,6,10,16,21-22)}$.

Um dado importante Que pode ter influência sobre a adesão dos trabalhadores aos EPI, refere-se à disponibilização dos mesmos no ambiente de trabalho. Os eQuipamentos de proteção individual necessários para a realização das atividades são fornecidos pela instituição, porém nem todos estão disponíveis na unidade, estão armazenados na farmácia hospitalar. E válido ressaltar Que de acordo com a NR $32^{(9)}$, os Equipamentos de Proteção Individual deverão estar à disposição do trabalhador, em número suficiente, nos postos de trabalho.

Acredita-se que a disponibilidade destes dispositivos no lócus do trabalho pode favorecer a adesão, pois gera economia de tempo e prevenção efetiva, na medida em Que estão junto à ocorrência da possível exposição. Assim manifestaram-se os sujeitos, Quanto a disponibilidade dos EPI:

[os EPI] Estão disponíveis se Quiser. Tem gente que não usa. Se Quiser tu vai lá e pega, se não Quiser tu não pega. EPI não ficam na unidade, ficam na farmácia, ai tem Que ir lá buscar. Tipo, Quando é paciente respiratório, tu vai lá e busca máscara e fica usando a máscara. Óculos; alguns nós temos aqui. (E8)

\section{Contribuições da equipe de enfermagem e dos gestores para} a prevenção dos acidentes de trabalho por material biológico

Quando Questionados acerca do Que poderia ser feito para Que os acidentes sejam evitados, a calma e a atenção foram as respostas predominantes, o Que se pode inferir Que o trabalhador têm consciência de Que a prevenção de grande parte dos acidentes do trabalho está ao seu alcance.

Usar os EPI's adequados e sempre fazer as coisas com calma e prestar bastante atenção. (E I0)

Eu acho Que todo muito tem Que estar prestando atenção no Que vai fazer, tem Que estar ligado, porQue Querendo ou não se agente tá voando no mundo da lua aí Que acontecem os acidentes, se a gente está concentrado no Que está fazendo não tem como tu se picar ou coisa assim. (E I4)

A falta de atenção e a pressa também foi verificado em estudo realizado em São Paulo ${ }^{(23)}$, como fatores determinantes de acidentes de trabalho, destacados pela equipe de enfermagem, fortalecendo a idéia de Que o trabalhador está ciente de sua contribuição na prevenção ou ocorrência dos mesmos. Deve-se atentar para esse dado, pois a educação em saúde é um dispositivo usado na instituição, porém ainda são praticadas ações inseguras. As falas remetem a um Questionamento: Que condicionantes estão envolvidos nesta falta de atenção dos trabalhadores? Não foi objetivo deste estudo, explorar esta variável, mas pode ser relevante investigar-se sobre isso, na medida em Que a atenção é uma função psíQuica fundamental na orientação do indivíduo e, conseQuentemente na prevenção de acidentes a si e aos outros.

Por meio da observação verificou-se Que a lavagem das mãos não ocorre com a frequência recomendada por grande parte dos trabalhadores, ou seja, antes e após o uso de luvas, conforme 
preconizado pela NR $32^{(9)}$. Outro dado Que demonstra a negligência do trabalhador, a falta de atenção a uma medida considerada de extrema importância na prevenção de infecções e, conseQuentemente, na promoção da segurança do usuário e do trabalhador.

Ao investigarem-se os aspectos pertinentes as contribuições do empregador no Que diz respeito à prevenção dos acidentes de trabalho por material biológico, pode-se inferir Que este contribui tanto para a prevenção Quanto para a ocorrência dos acidentes por material biológico. Para a grande maioria dos entrevistados o empregador oferece programas de educação continuada e saúde ocupacional frequentemente, desempenhando adequadamente seu papel educativo na prevenção de agravos ocupacionais e em acordo com a recomendação da NR $32^{(9)}$. Importante é referir Que a educação permanente/continuada é desenvolvida pelas enfermeiras da instituição, com a participação de colaboradores de outras áreas, e como uma estratégia bem sucedida.

[... eles sempre tão incentivando, nos motivando a comparecer nas palestras, tudo que eles têm. (E4)

De vez em Quando tem palestras sobre isso orientando, informando. (E 5)

todo mês a gente sempre tem educação continuada. (E I I)

Percebe-se, a partir das expressões verbais dos trabalhadores Que há educação em saúde de forma continuada/permanente, em consonância com a NR Que regulamenta Que em todo local onde exista a possibilidade de exposição a agentes biológicos, devem ser fornecidas aos trabalhadores instruções escritas, em linguagem acessível, das rotinas realizadas no local de trabalho e medidas de prevenção de acidentes e de doenças relacionadas ao trabalho.

Num estudo realizado com seis enfermeiras Que desenvolvem atividades gerenciais junto a um hospital de ensino foi evidenciado Que os sujeitos atribuem importância significativa à educação continuada/permanente desenvolvida junto aos recursos humanos considerando Que com esta prática, concede-se oportunidade de aprendizagem, aprimoramento profissional e autodesenvolvimento. Sob os princípios da globalização, foi observado pelas empresas, entre estas os hospitais, Que a excelência de atuação dos profissionais está no investimento e na exploração da capacidade de aprendizagem de seus profissionais em todos os níveis da organização(24).

Não foi intenção deste estudo verificar a forma em Que a prática da educação em saúde é desenvolvida, se educação continuada ou educação permanente em saúde, nem a adesão dos trabalhadores à prática, porém pode-se constatar Que é expressiva a oferta da prática educativa na instituição.

\section{A gestão de enfermagem contribuindo para a prevenção de acidentes com material biológico}

Entre os depoimentos surgem relatos acerca da necessidade de uma atitude da gerência de enfermagem para Que as condições de trabalho sejam melhoradas, principalmente do enfermeiro responsável pela unidade. Note-se Que o trabalhador espera de sua gerência atitudes de orientação, de educação, de exemplo, mas também de regulação e de fiscalização, conforme demonstrado nas falas:
Acho Que uma cobrança mais firme do funcionário, iria diminuir bastante [a negligência ao uso da EPI]. Atitudes do tipo se ver funcionário sem luva durante um procedimento, ir lá e chamar a atenção, dar uma advertência; ou avisar[educar] e depois dar advertência se não usar. (E8)

Ter educação continuada, usar EPI e sempre ter alguém orientando ali, começando pelo enfermeiro, Que tem Que dizer Que tem que usar EPI, ensinar o que é correto, o que é errado; e a pessoa principalmente ter consciência de onde ela trabalha . (EI0)

Considerando-se a categoria profissional, observa-se em alguns estudos $^{(10,23)}$ Que o enfermeiro também é acometido por parcela significativa de acidentes de trabalho. Algumas indagações extraemse destes dados, tais como: são sujeitos passíveis de desatenção, assim como outro profissional; estão expostos aos riscos biológicos da mesma forma e, também a estes profissionais lhes são oferecidas condições inadequadas de trabalho. Proposições a serem refletidas em outra investigação.

Considera-se pertinente expor uma situação referida e observada, a sobrecarga do profissional de enfermagem, a Qual pode ser uma condição facilitadora para a ocorrência de acidentes e, também, de atribuição dos gestores, seja administrativo ou técnico, refletirem para intervir. Embora a maioria dos entrevistados concorde e aprove as atitudes dos gestores na prevenção dos acidentes, atribuindo ao próprio trabalhador o principal responsável pela ocorrência dos mesmos, uma parcela significativa dos sujeitos ressaltou a sobrecarga de trabalho como fator de risco para acidentes, uma vez Que a unidade conta com um número reduzido de trabalhadores da equipe de enfermagem, o Que favorece imperícias, imprudências e negligências nas práticas.

Eu acho Que há sobrecarga, às vezes tu tem muito paciente e pouco tempo pra fazer as coisas [...] (E I6)

Se tivesse mais funcionários, eu trabalho no turno da noite, teria menos correria, a gente podia se dedicar mais ao paciente e se dedicando mais ao paciente a gente teria mais cuidado pra realizar o serviço. Eu acho que se tivesse o número certo de funcionários para os pacientes que nós temos aqui na clínica não ocorreria tanto esses riscos. (E I 4)

A sobrecarga de trabalho já foi citada em outros estudos sobre acidentes de trabalho com a equipe de enfermagem como potencializadora para a ocorrência dos mesmos, considerando que se configura como um risco psicossocial ${ }^{(10,16)}$ Que desgasta o trabalhador e o expõe a outros riscos.

Muitas instituições de saúde trabalham com a escassez de recursos humanos, o Que determina alteração no ritmo de trabalho. Sendo assim o tipo da unidade de trabalho pode ser um gerador da exposição aos fluidos biológicos, Que associada ao ritmo acelerado de trabalho, número reduzido de trabalhadores e a inadequação de recursos materiais desencadeiam processos de sofrimento ${ }^{(25)} \mathrm{e}$ adoecimento.

É importante, ainda salientar Que, semelhante a outros $\operatorname{estudos}^{(10,23)}$, outro fato Que merece destaque é a subnotificação 
do acidente à CIPA e à CCIH da instituição. Em geral, os serviços responsáveis pela notificação foram comunicados do acidente com material biológico, embora um número significativo referisse não ter informado a ocorrência do acidente, contribuindo para a subnotificação.

A NR 32 estatui Que os acidentes ou incidentes com material biológico devem ser comunicados imediatamente, ao responsável pelo local de trabalho, ao serviço de segurança e saúde do trabalho e à CIPA. A falta da notificação do acidente dificulta a reflexão sobre dados estatísticos do agravo. Números apenas, não bastam para Que diminuam ocorrências de acidentes por exposição biológica, contudo auxiliam na busca dos fatores causais e na criação de políticas de prevenção e promoção da saúde do trabalhador.

Pode-se constatar pela observação, Que algumas condições sanitárias ou de segurança do ambiente de trabalho não estão adeQuadas conforme a NR $32^{(9)}$, o Que de alguma forma contribui para a exposição aos riscos biológicos. Acredita-se Que a observância de condições satisfatórias da área física ou da adeQuação de mobiliário, equipamentos ou outras condições com vistas à segurança do trabalhador e do usuário é atribuição dos gestores da instituição, Que junto aos trabalhadores e por meio de discussões democráticas e emancipatórias, devem refletir e agir sobre estas condições, possibilitando ambiências saudáveis. Por meio da observação, pode-se verificar Que, entre outros.

Os quartos, inclusive aqueles determinados pela unidade para isolar pacientes com doenças transmissíveis, não apresentam lavatório exclusivo para higiene das mãos provido de água corrente, sabonete líquido, toalha descartável e lixeiras com sistema de abertura sem contato manual; a NR $32^{(9)}$ estatui Que tais condições sejam oferecidas em locais onde possa existir possibilidade de exposição o agente biológico. Os colchões, colchonetes e demais almofadados são revestidos de material lavável e impermeável, permitindo desinfecção e fácil higienização como preconiza a norma; porém alguns apresentam furos, sulcos e reentrâncias Que dificultam a limpeza, em desacordo com a referida norma.

Observou-se o consumo de alimentos e bebidas (água e refrigerantes) no posto de enfermagem da unidade, em desacordo com a NR $32^{(9)}$, Que determina um espaço para este fim. De acordo com a norma, os estabelecimentos com até 300 trabalhadores devem possuir locais para refeição, Que atendam entre outros requisitos a localização fora da área do posto de trabalho.

\section{CONSIDERAÇÕES FINAIS}

A reflexão acerca da vivência e a compreensão da realidade das atividades laborais dos trabalhadores de saúde da instituição e estudo possibilitou uma reflexão Que pode contribuir para a adoção e implementação de medidas Que efetivamente oportunizem a prevenção dos acidentes de trabalho e a observância das normas de biossegurança.

Percebeu-se através desta pesquisa que os profissionais têm consciência dos riscos aos Quais estão expostos em decorrência de suas atividades laborais; Que, embora os EPI sejam disponibilizados pelo empregador, um número significativo de participantes admitiu não utilizá-los, o Que denuncia a negligência do trabalhador como causa importante de ocorrência de acidentes de trabalho. No Que tange às contribuições dos trabalhadores para Que as exposições aos riscos com material biológico sejam evitadas, os mesmos reconhecem que estando atentos ao trabalho e tendo calma ao realizar suas atividades, acidentes podem ser reduzidos, entre outros achados.

Sendo assim, pode-se tecer algumas considerações acerca dos riscos a Que estão expostos os trabalhadores e os usuários, considerando-se Que, ao negligenciar o uso de EPI, o trabalhador expõe a si e a outrem, especialmente Quando tem conhecimento e consciência acerca da importância do uso.

Além disso, os dados apontam outras vulnerabilidades deste trabalhador. Ao trabalhar sob condições inseguras, seja por não adesão às precauções universais , seja por sobrecarga de atividades, seja por condições físicas insalubres o trabalhador fragiliza-se, o Que favorece o adoecimento.

Isto posto, estabelecer parcerias entre instituições Que legislam e fiscalizam a atenção à saúde do trabalhador, não basta para Que condutas e atitudes sejam transformadas. Acredita-se que há de se investir na educação de jovens ingressantes nos cursos de saúde e no incentivo às práticas e reflexões Que demonstrem as múltiplas vulnerabilidades em Que se encontram os profissionais de saúde.

Uma reflexão acurada sobre habilidades individuais e coletivas para a regulação do risco é fundamental; ao indivíduo trabalhador ou gestor deve ser dado o espaço Que lhe é devido, enQuanto ator na produção do cuidado, de responsabilização pelo dano á si e/ou ao trabalhador e ao usuário do serviço, em casos de negligência às normas de biossegurança, bem como de contribuição para a criação de ambientes saudáveis. Dimensionamento adequado de pessoal, EPI disponíveis ao funcionamento das atividades da enfermagem no local de trabalho e vigilância das condições sanitárias parecem ser, a partir do exposto neste estudo, ações prioritárias para a promoção da saúde do trabalhador e do usuário.

Espera-se Que este estudo sirva como reflexão para a prevenção de acidentes biológicos em serviços de saúde e para a promoção da saúde do trabalhador. Sugerem-se pesquisas Que investiguem fatores motivacionais para a desatenção ao uso de EPI, considerando a prevalência significativa desta prática entre os trabalhadores da enfermagem, no contexto estudado.

\section{REFERÊNCIAS}

1. Ministério da Saúde (BR). Agência Nacional de Vigilância Sanitária. Biossegurança. Rev Saúde Pública 2005; 39(6): 989-91

2. Ministério da Saúde (BR). Fundação Oswaldo Cruz -FIOCRUZProcedimentos para a manipulação de microorganismos patogênicos e/ou recombinantes. Rio de Janeiro: FIOCRUZ; 2005.
3. Gir E, Takahashi RF, Oliveira MAC, Nichiata LYI, Ciosak SI. Biossegurança em DST/AIDS: condicionantes da adesão do trabalhador de enfermagem ás precauções. Rev Esc Enferm USP 2004; 38(3): 245-53.

4. Souza, M. Assistência de Enfermagem em Infectologia. São Paulo: Atheneu; 2000. 
5. Brevidelli MM, Cianciarullo TI. Análise dos acidentes com agulhas em um hospital universitário:situações de ocorrência e tendências. Rev Latino-am Enfermagem 2002; 10(6): 780-6.

6. Sadoh WE, Fawole AO, Sadoh AE, Oladimeji AO, Sotiloye OS Practice of universal precautions among healthcare workers. I Nat Med Assoc 2006; 98(5): 722-6.

7. Almeida CAF, Benatti MCC. Exposições ocupacionais por fluidos corpóreos entre trabalhadores da saúde e sua adesão à Quimioprofilaxia. Rev Esc Enferm USP 2007; 4I (1): 120-6

8. Organização Pan-Americana da Saúde. Ministério da Saúde do Brasil(BR). Doenças relacionadas ao trabalho: manual de procedimentos para os serviços de saúde /Ministério da Saúde do Brasil, Organização Pan-Americana da Saúde no Brasil. Brasília: Ministério da Saúde; 2001 .

9. Ministério do Trabalho e Emprego (BR). Normas Regulamentadoras. Norma Regulamentadora no. 32. Segurança e Saúde no Trabalho em Estabelecimentos de Saúde. Brasília: Ministério do Trabalho e Emprego; 2005.

10. Ribeiro EJG, Shimizu HE. Acidentes de trabalho com trabalhadores de enfermagem. Rev Bras Enferm 2007; 60(5): 535-40.

11. Kondro W. The hazards of nursing. CMAJ 2007; 176(4): 437.

12. Polit DF, Hungler BP. Fundamentos de pesquisa em enfermagem. $3^{\text {a }}$ ed. Porto Alegre: Artes Médicas; 1995.

13. Ministério da Saúde (BR). Conselho Nacional de Saúde. Resolução 196/96 [citado em 02 out 2008] Disponível em: http:// www.datasus.gov.br/conselho/resol96

14. Minayo MCS. O Desafio do conhecimento: pesquisa Qualitativa em saúde. São Paulo: Hucitec; 2008.

15. Carvalho MB, Felli VEA. O trabalho de enfermagem psieuiátrica e os problemas de saúde dos trabalhadores. Rev Latino-am Enfermagem 2006; 14(1): 61-9.

16. Tomazin CC, Benatti MCC. Acidente de trabalho por material perfurocortante em trabalhadores de enfermagem. Rev Gaúcha Enferm 200I; 22(2): 60-73.

17. Pinho DLM, Rodrigues CM, Gomes GP. Perfil dos acidentes de trabalho no Hospital Universitário de Brasília. Rev Bras Enferm 2007; 60(3): 29l-4.

18. Sêcco IAO, Robazzi MLCC, Shimizu DS, Rúbio MMS. Acidentes de trabalho típicos envolvendo trabalhadores de hospital universitário da região sul do Brasil: epidemiologia e prevenção. Rev Latino-am Enfermagem 2008; 16(5): 824-831.

19. Braga D. Acidente de trabalho com material biológico em trabalhadores da equipe de enfermagem do Centro de Pesquisas Hospital Evandro Chagas [dissertação]. Rio de Janeiro: Fundação Oswaldo Cruz, Escola Nacional de Saúde Pública; 2000.

20. Beghdadli B, Belhadj Z, Chabane W, Ghomari O, Kandouci $A B$, Fanello $S$. Standard precautions" practices among nurses in a university hospital in Western Algeria. Sante Publique 2008; 20(5): 445-53.

21. Ganczak M, Szych Z. Surgical nurses and compliance with personal protective equipment. I Hosp Infect 2007; 66(4): 346-5I.

22. Costa LFV, Freitas MIP. Reprocessamento de artigos críticos em unidades básicas de saúde: perfil do operador e ações envolvidas. Rev Bras Enferm 2009; 62(6): 81 I-19.

23. Nishide VM, Benatti MCC, Alexandre NMC. Ocorrência de acidente do trabalho em uma unidade de terapia intensiva. Rev Latino-am Enfermagem 2004; 12(2): 204-I I.

24. Lima AF, Kurganct P. Indicadores de Qualidade no gerenciamento de recursos humanos em enfermagem. Rev Bras Enferm 2009; 62(2): 234-2

25. Sarquis LMM, Felli VEA. Os sentimentos vivenciados após exposição ocupacional entre trabalhadores de saúde: fulcro para repensar o trabalho em instituições de saúde. Rev Bras Enferm 2009; 62(5): 70I-4. 